\title{
The Epitranscriptome in Translation Regulation
}

\author{
Eyal Peer, Sharon Moshitch-Moshkovitz, Gideon Rechavi, and Dan Dominissini \\ Sackler School of Medicine, Tel Aviv University, Tel Aviv 6997801, Israel; Cancer Research Center and \\ Wohl Centre for Translational Medicine, Chaim Sheba Medical Center, Tel-Hashomer 5262160, Israel \\ Correspondence: dan.dominissini@sheba.health.gov.il
}

The cellular proteome reflects the total outcome of many regulatory mechanisms that affect the metabolism of messenger RNA (mRNA) along its pathway from synthesis to degradation. Accumulating evidence in recent years has uncovered the roles of a growing number of mRNA modifications in every step along this pathway, shaping translational output. mRNA modifications affect the translation machinery directly, by influencing translation initiation, elongation and termination, or by altering mRNA levels and subcellular localization. Features of modification-related translational control are described, charting a new and complex layer of translational regulation.

C ellular homeostasis requires regulation of protein levels, as impaired regulation can result in cellular death or dysregulated proliferation (Hershey et al. 2012). Protein levels are a consequence of three fundamental factors: the abundance of messenger RNA (mRNA), the efficiency of translation, and protein stability. First isolated from ribosomal RNA (rRNA) almost seven decades ago (Cohn 1951), modified RNA bases were later also discovered to be abundant constituents of mRNA, with $\mathrm{N}^{6}$ methyladenosine $\left(\mathrm{m}^{6} \mathrm{~A}\right)$ as the most prevalent internal mRNA modification (Desrosiers et al. 1974). To date, 170 different modified nucleotides have been identified in RNA from all types and species (Boccaletto et al. 2018), expanding the RNA alphabet to embed transcripts with additional information. The introduction of transcriptome-wide mapping methods and the discovery of enzymes capable of removing $\mathrm{m}^{6} \mathrm{~A}$ and of dedicated $\mathrm{m}^{6} \mathrm{~A}$-binding proteins have introduced the novel notion that internal chemical modifications of mRNA and long noncoding RNA (lncRNA) are potentially dynamic and sometimes reversible events, which constitute essential regulatory elements in basic RNA-processing steps such as splicing, transport, translation, and decay. The epitranscriptome, as this ensemble is now known, comprises a growing number of chemical adducts: $\mathrm{m}^{6} \mathrm{~A}$, inosine (I), 5-methylcytidine $(5 \mathrm{mC}), 5$-hydroxymethylcytidine $(5 \mathrm{hmC})$, pseudouridine $(\Psi), 2^{\prime}$-O-methylation $(\mathrm{Nm})$, and $N^{1}$-methyladenosine $\left(\mathrm{m}^{1} \mathrm{~A}\right)$. This review focuses on $\mathrm{m}^{6} \mathrm{~A}$ as well as on more recently characterized mRNA modifications and their effects on translation.

\section{$N^{6}$-METHYLADENOSINE $\left(\mathrm{m}^{6} \mathrm{~A}\right)$}

$\mathrm{m}^{6} \mathrm{~A}$ is the most common internal (noncap) mRNA modification found in eukaryotic organisms as well as in RNA of nuclear-replicat-

Editors: Michael B. Mathews, Nahum Sonenberg, and John W.B. Hershey

Additional Perspectives on Translation Mechanisms and Control available at www.cshperspectives.org

Copyright (C) 2019 Cold Spring Harbor Laboratory Press; all rights reserved; doi: 10.1101/cshperspect.a032623

Cite this article as Cold Spring Harb Perspect Biol 2019;11:a032623 
ing viruses (reviewed in $\mathrm{Fu}$ et al. 2014). $\mathrm{m}^{6} \mathrm{~A}$ constitutes $0.1 \%-0.5 \%$ of adenosine residues in mRNA, corresponding to $\sim 3-5 \mathrm{~m}^{6} \mathrm{~A}$ modifications per transcript. Although $\mathrm{m}^{6} \mathrm{~A}$ was discovered in mRNA decades ago (Desrosiers et al. 1974), its study was jump-started in recent years with the identification of the $\mathrm{m}^{6} \mathrm{~A}$-specific demethylases: the fat mass and obesity-associated protein (FTO) and AlkB homolog 5 (ALKBH5) (Jia et al. 2011; Zheng et al. 2013), followed by the development of high-throughput $\mathrm{m}^{6} \mathrm{~A}$ mapping tools, $\mathrm{m}^{6} \mathrm{~A}$-seq (Dominissini et al. 2012) and methylated RNA immunoprecipitation and sequencing (MeRIP-Seq) (Meyer et al. 2012). Transcriptome-wide mapping of $\mathrm{m}^{6} \mathrm{~A}$ revealed an evolutionarily conserved, nonrandom distribution (Dominissini et al. 2012; Meyer et al. 2012); $\mathrm{m}^{6} \mathrm{~A}$ preferentially decorates $5^{\prime}$ untranslated regions (UTRs), long internal exons, and the vicinity of stop codons. Sites preferentially appear within the consensus sequence RRACU $(\mathrm{R}=\mathrm{A}$ or $\mathrm{G})$ (Dominissini et al. 2012).

The deposition of $\mathrm{m}^{6} \mathrm{~A}$ in mRNA is performed by a multicomponent methyltransferase complex of which several components have been identified: methyltransferase-like 3 (METTL3), the catalytic component; methyltransferaselike 14 (METTL14), an RNA adaptor needed for METTL3 activity; Wilms Tumor 1-associating protein (WTAP), a regulatory factor that is also responsible for nuclear speckle localization; RNA-binding motif (RBM) proteins 15/15B (RBM15/15B), mediators of methylation specificity by directing the complex to specific transcripts; and KIAA1429/Virilizer, whose function is still unclear (reviewed in Meyer and Jaffrey 2017).

The balance between writing (adding) and erasing $\mathrm{m}^{6} \mathrm{~A}$ from transcripts confers upon this modification a dynamic nature, which is evident under stress conditions (Dominissini et al. 2012), supporting a role in regulation of gene expression. Indeed, $\mathrm{m}^{6} \mathrm{~A}$ plays a role in many aspects of gene expression, affecting RNA splicing, nuclear export and retention, translation, and turnover. The major mechanism by which $\mathrm{m}^{6} \mathrm{~A}$ exerts its effects is by recruiting $\mathrm{m}^{6} \mathrm{~A}$ reader proteins: fragile $\mathrm{X}$ mental retardation 1 (FMR1) (Edupuganti et al. 2017); YTH domain-contain- ing family protein 1 (YTHDF1) and YTH domain-containing family protein 3 (YTHDF3) (regulation of translation); YTH domain-containing family protein 2 (YTHDF2) (regulation of RNA turnover); and heterogeneous nuclear ribonucleoprotein A2/B1 (HNRNPA2B1) and YTH domain-containing 1 (YTHDC1) (processing of primary microRNAs and alternative splicing) (Meyer and Jaffrey 2017). These discoveries opened up the field of epitranscriptomics for accelerated investigation.

\section{PSEUDOURIDINE ( $\Psi)$}

$\Psi$ was the first posttranscriptional modification to be identified and, taking all classes of RNA into account, is also the most abundant. Recently it was shown to be more abundant in mRNA than previously believed, with a $\Psi / U$ ratio of $0.2 \%-0.6 \%$ in mammalian mRNA ( $\mathrm{Li}$ et al. 2015). It is formed by isomerization of uridine in which the base is rotated $180^{\circ}$ along the N3-C6 axis. Although the modified base has unaltered Watson-Crick base-pairing properties, it gains an additional hydrogen-bond donor at its nonWatson-Crick edge, thus endowing it with distinct chemical properties (Ge and Yu 2013). $\Psi$ plays roles in the biogenesis and function of spliceosomal small nuclear RNAs (snRNAs) and rRNA. Methods for transcriptome-wide mapping of $\Psi$ using $\Psi$-specific chemical labeling by CMC [ $N$-cyclohexyl- $N^{\prime}$-(2-morpholinoethyl) carbodiimide metho- $p$-toluenesulfonate] identified hundreds of $\Psi$ sites in yeast and human mRNAs (Carlile et al. 2014; Schwartz et al. 2014; Li et al. 2015). No preferred localization of $\Psi$ to specific regions of mRNA was shown.

Installation of $\Psi$ is catalyzed by pseudouridine synthases (PUSs) and can be achieved through two distinct mechanisms (Li et al. 2016a): (1) RNA-independent pseudouridylation that is catalyzed by a single PUS enzyme responsible for both substrate recognition and catalysis; or (2) RNA-dependent pseudouridylation that relies on RNA-protein complexes consisting of box H/ACA noncoding RNAs in conjunction with the centromere-binding factor 5 (Cbf5)/ Dyskerin protein complex. Although mRNA $\Psi$ is dynamically regulated in response to environ- 
mental signals (Carlile et al. 2014), pseudouridylation has not been shown to be reversible.

\section{$N^{1}-$ METHYLADENOSINE $\left(\mathrm{m}^{1} \mathrm{~A}\right)$}

Using mass spectrometry and a mapping methodology based on immunocapture and massively parallel sequencing, $\mathrm{m}^{1} \mathrm{~A}$ was recently identified as a new epitranscriptome marker that occurs on thousands of human and mouse mRNAs (Dominissini et al. 2016; Li et al. 2016b). $\mathrm{m}^{1} \mathrm{~A}$ was known to exist in transfer RNA (tRNA) and rRNA and is unique in that it has both a methyl group and a positive charge under physiological conditions, which could markedly alter RNA structure and protein-RNA interactions. Transcriptome-wide mapping of $\mathrm{m}^{1} \mathrm{~A}$ revealed unique features of its distribution that strongly indicate functional roles: (1) $\mathrm{m}^{1} \mathrm{~A}$ is strongly enriched in mRNA 5'UTRs, close to translation initiation sites; (2) $\mathrm{m}^{1} \mathrm{~A}$ is present in highly structured regions of $5^{\prime} \mathrm{UTRs}$; (3) $\mathrm{m}^{1} \mathrm{~A}$ positively correlates with translation efficiency and protein levels; (4) the distribution of $\mathrm{m}^{1} \mathrm{~A}$ is highly conserved in all mouse and human cell types examined; and (5) $\mathrm{m}^{1} \mathrm{~A}$ is dynamic in response to stress and physiological signals, and its level varies across tissues (Dominissini et al. 2016; Li et al. 2016b). Together, these attributes suggest a positive and dynamic role for $\mathrm{m}^{1} \mathrm{~A}$ in translation initiation in mammalian cells.

A recently improved detection method identified hundreds of $\mathrm{m}^{1} \mathrm{~A}$ sites with single-nucleotide resolution; most of them are in the mRNA $5^{\prime} \mathrm{UTR}$ (including a minor fraction in the first transcribed nucleotide, cap +1 ), validating and refining earlier studies. Sites fall into three subsets defined by their location, the identity of the writer enzyme, and sequence-structure features: TRMT6/61A-independent and-dependent $\mathrm{m}^{1} \mathrm{~A}$ sites in nuclear-encoded mRNA; and tRNA methyltransferase 61B (TRMT61B)-dependent $\mathrm{m}^{1} \mathrm{~A}$ sites in mitochondrial-encoded mRNA. tRNA methyltransferase 6 (TRMT6)/ tRNA methyltransferase 61A (TRMT61A)-independent $\mathrm{m}^{1} \mathrm{~A}$ sites constitute the largest subset and are strongly enriched in the $5^{\prime} \mathrm{UTR}$. TRMT6/61A-dependent $\mathrm{m}^{1} \mathrm{~A}$ sites conform to a GUUCRA tRNA-like motif $(\mathrm{R}=\mathrm{A}$ or $\mathrm{G})$ and have T-loop-like structures, are evenly distributed along transcript segments, and constitute roughly $10 \%$ of all identified sites. Last, TRMT61B-dependent $\mathrm{m}^{1} \mathrm{~A}$ sites are primarily located within the coding region of mitochondrial mRNA, where they inhibit translation (Li et al. 2017b).

\section{2'-O-METHYLATION (Nm)}

The ribose ring can be methylated at the $2^{\prime}$ position to form $\mathrm{Nm}$ (Boccaletto et al. 2018), an abundant modification present in mRNA, rRNA, tRNA, snRNA, and microRNA, which is essential for their biogenesis, metabolism, and function (Liang et al. 2009; Daffis et al. 2010; Lin et al. 2011; Züst et al. 2011; Deryusheva et al. 2012; Jöckel et al. 2012; Somme et al. 2014). Nm modification is catalyzed either by stand-alone methyltransferases that recognize their targets according to sequence and structure (Somme et al. 2014), or by the enzyme fibrillarin, part of a ribonucleoprotein complex that is guided to its targets by different C/D-box small nucleolar RNAs (snoRNAs) (Shubina et al. 2016). Nm also occurs at the $5^{\prime}$ cap (Byszewska et al. 2014) and internal positions of non-rRNA transcripts (Lacoux et al. 2012). 2'-O-methylation endows nucleotides with greater hydrophobicity, protects against nucleolytic attack, and stabilizes RNA helices (Kumar et al. 2014; Yildirim et al. 2014).

In higher eukaryotes, the $5^{\prime}$ penultimate (the first transcribed) and antepenultimate (the second transcribed) nucleotides in mRNA $\left(\mathrm{m}^{7} \mathrm{GpppNmNm}\right)$ may be $2^{\prime}-O$-methylated by stand-alone enzymes that recognize the cap. Aside from these $\mathrm{Nm}$ sites, accumulating evidence suggests that internal positions in mRNA can also be $2^{\prime}$-O-methylated (Gumienny et al. 2016). This possibility is especially intriguing in light of the consequences that such modification could have when present in the coding sequence (CDS) (Hoernes et al. 2016).

A recently developed $\mathrm{Nm}$ mapping method, $\mathrm{Nm}$-Seq, uncovered thousands of $\mathrm{Nm}$ sites in human mRNA, with Um being the dominant species (Dai et al. 2017). Nm sites are enriched 
in the $3^{\prime} U T R$ and around internal splice sites. In the CDS, the sites are nonrandomly distributed with $60.4 \%$ of them occurring in only six codons, suggesting functional roles.

\section{$N^{6}, 2^{\prime}-O$-DIMETHYLADENOSINE ( $\left.{ }^{6} \mathrm{Am}\right)$}

The $5^{\prime}$ end of mRNA transcripts is modified by an $N^{7}$-methylguanosine $\left(\mathrm{m}^{7} \mathrm{G}\right)$ cap and $2^{\prime}-O$ methylation $(\mathrm{Nm})$ of the ribose sugar of the first, and sometimes the second, transcribed nucleotides (Keith et al. 1978) as mentioned above. Cap-associated modifications recruit translation initiation factors to mRNA and allow the cell to discriminate host from viral mRNA, 2'-O-methylation being especially important for the latter (Daffis et al. 2010). When the first transcribed nucleotide (the $5^{\prime}$ penultimate base) is Am, it can be further methylated at the $N^{6}$ position by an unidentified methyltransferase to form $\mathrm{m}^{6} \mathrm{Am}$ (Keith et al. 1978). Taking advantage of the affinity for $\mathrm{m}^{6} \mathrm{Am}$ of an antibody raised against $\mathrm{m}^{6} \mathrm{~A}$, hundreds of $\mathrm{m}^{6} \mathrm{Am}$ sites in mRNAs have recently been mapped (Lacoux et al. 2012). $\mathrm{m}^{6} \mathrm{Am}$ in the $5^{\prime}$ cap is dynamic and reversible; it can be demethylated to Am by FTO (Mauer et al. 2017) to affect transcript decapping and thereby mRNA stability.

\section{5-METHYLCYTIDINE (5mC) AND 5-HYDROXYMETHYLCYTIDINE (5hmC)}

Methylation of cytosine at the fifth position was identified in mRNA more than 40 years ago (Dubin and Taylor 1975; Dubin et al. 1977) but other studies failed to recapitulate the finding (Desrosiers et al. 1975; Wei et al. 1976) and some have hypothesized that the detection of $5 \mathrm{mC}$ in mRNA was merely because of contamination from other RNA species (Bokar 2005). However, appropriating bisulfite sequencing-a method used in mapping $5 \mathrm{mC}$ in DNA-for transcriptome-wide mapping of $5 \mathrm{mC}$ in RNA confirmed $5 \mathrm{mC}$ as an mRNA modification and unveiled thousands of sites with nonrandom distribution (Squires et al. 2012; Amort et al. 2017). NOP2/Sun RNA methyltransferase family member 2 (NSUN2), a methyltransferase that installs $5 \mathrm{mC}$ in tRNA, was identified as re- sponsible for $5 \mathrm{mC}$ in some mRNAs as well (Hussain et al. 2013; Khoddami and Cairns 2013).

Recently, ALYREF, a nuclear export factor, has been identified as a reader of $5 \mathrm{mC}$ in $\mathrm{mRNA}$ (Yang et al. 2017a). Although it is not known to be completely reversible, it was discovered that $5 \mathrm{mC}$ in RNA undergoes oxidation by the ten-eleven translocation (Tet) protein family (TET1,2,3) to produce 5hmC (Fu et al. 2014). Transcriptome-wide mapping of $5 \mathrm{hmC}$ in Drosophila melanogaster was performed by adapting MeRIP-seq to 5hmC (hMeRIP-seq), and yielded over 3000 putative $5 \mathrm{hmC}$ sites in mRNA. Although the function of $5 \mathrm{hmC}$ is unclear, ribosomal profiling (see Ingolia et al. 2018) revealed that $5 \mathrm{hmC}$ is highly enriched in actively translated transcripts, suggesting that $5 \mathrm{hmC}$ may facilitate mRNA translation (Delatte et al. 2016).

\section{READING THE EPITRANSCRIPTOME}

RNA modifications exert their effects, both directly and indirectly, by altering the chemistry of RNA nucleotides. A modified RNA nucleotide can be specifically recognized by certain RNAbinding proteins, which then act as readers of the modification and determine the fate of the modified mRNA. When the effect is mediated by binding proteins, it is termed indirect. It can also stabilize or destabilize the structure of an RNA molecule, leading to a direct change in level, function, or even translation dynamics. The effect can also be mediated by a combination of direct and indirect mechanisms, where a change in RNA structure improves the accessibility for RNA-binding proteins. In addition, hydrophobic modifications incur a solvation penalty in water, which can be reduced by interaction with protein residues containing hydrophobic side-chains (Noeske et al. 2015; Roundtree et al. 2017).

Each modification carries distinct chemical implications. In $\mathrm{m}^{6} \mathrm{~A}$, methylation at the sixth position of the base does not alter hydrogenbonding donors and acceptors and does not appear to affect translational fidelity (You et al. 2017), but the added methyl group creates steric 
hindrance, thereby changing the energetics of the AU pair and destabilizing the pairing with uracil (Roost et al. 2015). In $\mathrm{m}^{1} \mathrm{~A}$, methylation at the $\mathrm{N}^{1}$ position results in a positive charge, potentially leading to strong electrostatic interactions (He et al. 2005). Additionally, and in contrast to $\mathrm{m}^{6} \mathrm{~A}$, the added methyl group protrudes from the Watson-Crick hydrogen-bonding face of adenine, causing the nucleotide to remain unpaired (Lu et al. 2010). Also in contrast with $\mathrm{m}^{6} \mathrm{~A}, \mathrm{~m}^{1} \mathrm{~A}$ appears to have the potential to block the translation machinery (You et al. 2017). In $\Psi$, although the isomerization does not change the Watson-Crick base-pairing, it does add another potential hydrogenbond donor to the base ( $\mathrm{Ge}$ and $\mathrm{Yu}$ 2013). Methylation of the ribose in $\mathrm{Nm}$ stabilizes RNA helices and augments the nucleotide's hydrophobicity, protecting it from nucleolytic attack (Kumar et al. 2014; Yildirim et al. 2014).

The direct and indirect mechanisms by which modifications affect mRNA metabolism and translation have been explored mainly for $\mathrm{m}^{6} \mathrm{~A} \cdot \mathrm{m}^{6} \mathrm{~A}$ can restructure RNA to control accessibility of sequence motifs to RNA-binding proteins. This dynamic interdependence between RNA structure and modification, termed the $\mathrm{m}^{6} \mathrm{~A}$-switch, has functional consequences. For example, heterogeneous nuclear ribonucleoprotein (hnRNP) $\mathrm{C}$ does not bind $\mathrm{m}^{6} \mathrm{~A}$ but rather a $\mathrm{U}$-tract opposing the $\mathrm{m}^{6} \mathrm{~A}$ site, made accessible by $\mathrm{m}^{6} \mathrm{~A}$. Global reduction of $\mathrm{m}^{6} \mathrm{~A}$ levels masks a significant subset of hnRNP C binding sites, thereby affecting hnRNP C's effect on alternative splicing (Liu et al. 2015).

Genuine direct $\mathrm{m}^{6} \mathrm{~A}$ readers have been discovered and studied, starting with identification of YTH domain family proteins as bona fide $\mathrm{m}^{6} \mathrm{~A}$ readers (Dominissini et al. 2012). The YTH domain is a highly conserved RNA-binding domain, identified in over 170 family members in a wide range of eukaryotes, from yeast and plants to vertebrates, appearing in five human proteins: YTHDF1-3 and YTHDC1-2 (Stoilov et al. 2002; Zhang et al. 2010). Initially characterized at the turn of the century (Imai et al. 1998), YTH was recently validated as an $\mathrm{m}^{6} \mathrm{~A}$ binding domain (Wang et al. 2014) and YTH domain family proteins were shown to mediate the effect of $\mathrm{m}^{6} \mathrm{~A}$ on mRNA stability (Wang et al. 2014; Du et al. 2016; Shi et al. 2017), translation (Wang et al. 2015; Li et al. 2017a; Shi et al. 2017), and processing (Xiao et al. 2016), as well as non-mRNA-related roles such as IncRNA-mediated transcriptional repression (Patil et al. 2016) and translation of circular RNA (circRNA) (Yang et al. 2017b; Chekulaeva and Rajewsky 2018). Although only the YTH domain has been structurally characterized in complex with $\mathrm{m}^{6} \mathrm{~A}$ ( $\mathrm{Li}$ et al. 2014; Luo and Tong 2014; Theler et al. 2014; Xu et al. 2014; Zhu et al. 2014), other $\mathrm{m}^{6} \mathrm{~A}$ readers have been suggested (Edupuganti et al. 2017; Huang et al. 2018).

\section{INDIRECT AND DIRECT EFFECTS OF mRNA MODIFICATIONS ON TRANSLATION}

The translation rate of a protein is proportional to the concentration and translational efficiency of its mRNA (Hershey et al. 2012). mRNA modifications define the proteome by influencing these two factors. They play a direct role by attracting translation initiation factors, influencing translation elongation and termination, and potentially recoding the genetic code, and an indirect role by altering mRNA stability, splicing, nuclear export, and subcellular localization.

\section{Indirect Effects}

The levels of mRNAs can be modulated by a change in their stability conferred by several mRNA modifications; the half-life of $\mathrm{m}^{6} \mathrm{~A}$ methylated transcripts is on average shorter than nonmethylated ones. Degradation of these transcripts is mediated by YTHDF2 that preferentially binds $\mathrm{m}^{6} \mathrm{~A}$-containing transcripts and moves them from translatable pools to P-bodies or stress granules (Wang et al. 2014). YTHDF2 recruits the CCR4-NOT deadenylase complex by directly interacting with CNOT1 to initiate deadenylation and mRNA degradation (Du et al. 2016; Heck and Wilusz 2018).

In contrast to $\mathrm{m}^{6} \mathrm{~A}$, the presence of $\mathrm{m}^{6} \mathrm{Am}$ (Cap1) in mRNA increases the stability of transcripts by conferring resistance to the mRNA decapping enzyme, DCP2. FTO is able to 
remove the methyl group from the $N^{6}$ position, thereby facilitating decapping and degradation (Mauer et al. 2017).

$\Psi$ also affects mRNA stability. In yeast, Pus7p pseudouridylates mRNA in response to heat shock. Depletion of Pus7p results in decreased stability of theses transcripts, supporting a role for $\Psi$ in mRNA degradation (Schwartz et al. 2014).

Translation is also affected by the availability of transcripts for ribosome binding. Thus, subcellular compartmentalization such as nuclear retention controls transcript availability. The effect of $\mathrm{m}^{6} \mathrm{~A}$ on the nuclear export of transcripts was shown by Fustin et al. (2013) who showed that reduced $\mathrm{m}^{6} \mathrm{~A}$ levels resulted in nuclear accumulation of otherwise methylated transcripts.

Axonal mRNA can be locally translated in response to specific signals, providing an effective mechanism for rapid protein synthesis. The nonnuclear pool of FTO in the axon regulates local translation of axonal mRNA by $\mathrm{m}^{6} \mathrm{~A}$ demethylation to increase transcript expression (Yu et al. 2017).

$5 \mathrm{mC}$ can also affect nuclear export of mRNA transcripts. Depletion of $5 \mathrm{mC}$ inhibits recognition of transcripts by the export adaptor ALYREF, an RNA-binding protein that preferentially binds 5mC-modified RNA, resulting in dysregulated nuclear export (Yang et al. 2017a).

\section{Direct Effects}

The effects of mRNA modifications on translation can take place at every stage of the translation process. These modifications can act by either altering base-pairing, inducing conformational changes, or modulating the recognition of RNA-binding proteins. Most of the data regarding mRNA modification emerge from $\mathrm{m}^{6} \mathrm{~A}$ studies. Although it does not affect hydrogen bonding or translational fidelity (You et al. 2017), accumulating evidence suggests that $\mathrm{m}^{6} \mathrm{~A}$ is involved in translation regulation through several mechanisms.

Transcriptome-wide mapping of $\mathrm{m}^{6} \mathrm{~A}$ identified a subset of $\mathrm{m}^{6} \mathrm{~A}$ sites that are located in the 5'UTR of mRNA (Dominissini et al. 2012; Meyer et al. 2012). The $5^{\prime}$ UTR is critical for ribo- some recruitment to mRNA. Typically, translation begins when the $43 \mathrm{~S}$ ribosomal complex is recruited to the $5^{\prime} 7$-methylguanosine $\left(\mathrm{m}^{7} \mathrm{G}\right)$ cap of mRNA transcripts through the cap-binding complex eukaryotic translation initiation factor 4F (eIF4F). Under stress conditions, a switch from canonical eukaryotic translation initiation factor $4 \mathrm{E}$ (eIF4E)-dependent to eIF4E-independent translation initiation can take place (see Kwan and Thompson 2018; Merrick and Pavitt 2018; Robichaud et al. 2018). Toeprinting experiments revealed that $\mathrm{m}^{6} \mathrm{~A}$ at the $5^{\prime} \mathrm{UTR}$ of mRNA transcripts can allow bypass of eIF4Edependency through the direct binding of eIF3, which is sufficient to recruit the $43 \mathrm{~S}$ complex to initiate translation (Meyer et al. 2015). These experiments showed that eIF3 preferentially binds mRNA transcripts that carry $\mathrm{m}^{6} \mathrm{~A}$ in the $5^{\prime} \mathrm{UTR}$, and that $\mathrm{m}^{6} \mathrm{~A}$-induced translation initiation occurs only in transcripts containing $\mathrm{m}^{6} \mathrm{~A}$ in the $5^{\prime} \mathrm{UTR}$ and not elsewhere within the transcript (including the cap-associated $\mathrm{m}^{6} \mathrm{Am}$ ).

Another line of evidence for the role of $\mathrm{m}^{6} \mathrm{~A}$ in translation initiation came from a study that showed direct binding of METTL3 to eIF3 (Lin et al. 2016). METTL3, a predominantly nuclear protein, is also present in the cytoplasm and recruits the ribosome through association with eIF3. This association is dependent on $m^{6} \mathrm{~A}$ methylation and independent of METTL3's methyltransferase activity, METTL14, WTAP, and other $\mathrm{m}^{6} \mathrm{~A}$ reader proteins, including YTHDF1 and YTHDF2. Reduced $\mathrm{m}^{6} \mathrm{~A}$ levels lead to decreased METTL3 binding to transcripts in the cytoplasm and consequently reduced protein levels (Lin et al. 2016). It is unclear whether METTL3 plays a role in capdependent or cap-independent translation.

The effect of $\mathrm{m}^{6} \mathrm{~A}$ in the $5^{\prime} \mathrm{UTR}$ on translation initiation was further established in a recent study (Coots et al. 2017) revealing that when eIF4F-dependent translation is impaired, cells use a different mode of translation that is neither cap- nor internal ribosome entry site (IRES)dependent, but rather $\mathrm{m}^{6} \mathrm{~A}$-dependent. This study identified ATP-binding cassette subfamily F member 1 (ABCF1) as a critical mediator of $\mathrm{m}^{6} \mathrm{~A}$-dependent, eIF4E-independent translation. $\mathrm{ABCF} 1$ serves as an alternative recruiter for the 
ternary complex during noncanonical translation by interacting with eIF2, which controls ternary complex formation (a rate-limiting step to the overall translational output) and ribosomes, proving its critical role for mRNA translation under stress (see Merrick and Pavitt 2018; Wek 2018). Interestingly, the synthesis of METTL3, required for installing $\mathrm{m}^{6} \mathrm{~A}$ in mRNA transcripts, is $\mathrm{m}^{6} \mathrm{~A}$ - and $\mathrm{ABCF} 1$-dependent, generating a positive feedback loop and providing a mechanism by which cells activate $\mathrm{m}^{6} \mathrm{~A}$-mediated translation on inhibition of capdependent translation.

The effect of $\mathrm{m}^{6} \mathrm{~A}$ on translation initiation involves additional $\mathrm{m}^{6} \mathrm{~A}$-binding proteins. Wang et al. (2015) have shown that a member of the YTH domain family is involved in $\mathrm{m}^{6} \mathrm{~A}$ mediated regulation of translation initiation. YTHDF1 binds $\mathrm{m}^{6} \mathrm{~A}$-modified transcripts and increases translation through interaction with eIF3 (Wang et al. 2015).

Although the effect of $\mathrm{m}^{6} \mathrm{~A}$ on translation initiation is mediated through its binding by different proteins, other modifications may act by affecting the structure of the $5^{\prime} \mathrm{UTR}$. A positively charged $\mathrm{m}^{1} \mathrm{~A}$ may alter the secondary/ tertiary structure of mRNA around translation initiation sites by blocking Watson-Crick basepairing or introducing charge-charge interactions. Alternatively, potential binding proteins may specifically recognize $\mathrm{m}^{1} \mathrm{~A}$ and facilitate translation initiation of methylated transcripts in a way analogous to the role of $\mathrm{m}^{6} \mathrm{~A}$ readers of the YTH domain family. Ribosome profiling and proteomic analyses revealed that $\mathrm{m}^{1} \mathrm{~A}$ sites in the $5^{\prime} \mathrm{UTR}$, but not those in the CDS or $3^{\prime} \mathrm{UTR}$, correlated with higher translation efficiency. The mechanisms by which $5^{\prime} \mathrm{UTR}$ $\mathrm{m}^{1} \mathrm{~A}$ sites affect translation efficiency are still unknown (Dominissini et al. 2016; Lin et al. 2016; Li et al. 2017b).

During translation elongation, $\mathrm{m}^{6} \mathrm{~A}$ in $\mathrm{mRNA}$ can act as a barrier to tRNA accommodation. The presence of an $\mathrm{m}^{6} \mathrm{~A}$ within a codon disrupts cognate tRNA selection, with the greatest effect at the most thermodynamically unstable steps of initial selection (Choi et al. 2016). $5 \mathrm{mC}$ and $\Psi$ also affect elongation rates in vitro, with in vitro transcribed mRNAs containing both $5 \mathrm{mC}$
The Epitranscriptome in Translation Regulation

and $\Psi$, requiring a longer time for synthesis of full-length proteins compared to unmodified mRNA (Svitkin et al. 2017).

Translation terminates when the ribosome reaches a nonsense codon (see Hellen 2018; Rodnina 2018). All three possible nonsense codons contain a uridine at the first position, and Karijolich and $\mathrm{Yu}$ (2011) have shown that pseudouridylation of this residue suppresses translation termination in vitro and in vivo. An in-depth structural study of the bacterial $30 \mathrm{~S}$ ribosomal subunit in complex with a pseudouridylated nonsense codon indicates formation of noncanonical base-pairing in the second and third positions (Fernandez et al. 2013). Although it is unclear whether this readthrough mechanism is used naturally, it could be of therapeutic importance, given that many genetic diseases can be attributed to premature translation termination yielding a dysfunctional protein (Karijolich and $\mathrm{Yu}$ 2011).

\section{MODIFICATIONS AND INNATE IMMUNITY: GLOBAL EFFECTS ON THE TRANSLATION MACHINERY}

Innate immunity, the initial immune response to pathogenic invasion, involves the activation of proteins that distinguish self from nonself by identification of pathogen-associated molecular patterns (PAMPs). DNA and RNA stimulate the mammalian innate immune system by activation of Toll-like receptors (TLRs), retinoic acid-inducible gene I (RIG-I), and the RNAactivated protein kinase R (PKR) (Nallagatla et al. 2011).

Similar to DNA-containing methylated CpG motifs, which do not stimulate TLRs, the modified nucleosides $5 \mathrm{mC}, \mathrm{m}^{6} \mathrm{~A}$, and $\Psi$ also ablate TLR activity (Kariko et al. 2005). Although $5^{\prime}$-triphosphate RNA is a ligand for RIG-I, $5^{\prime}$ capped or pseudouridylated RNA is not (Hornung et al. 2006; Wang et al. 2010). Consequently, pseudouridylated in vitro transcribed RNA shows significantly enhanced translation compared to nonmodified RNA, whereas a modest effect was also observed when incorporating $5 \mathrm{mC}$ (Kariko et al. 2008). Interestingly, enhanced translation was observed in rabbit 
E. Peer et al.

reticulocyte lysates, which contain the RNAdependent PKR, but not in wheat germ extracts, which do not (Davis and Watson 1996).

The improved translation of pseudouridylated mRNA is independent of RIG-I activity and further research showed that in vitro transcribed RNA-containing uridine activates PKR, which phosphorylates the $\alpha$ subunit of eIF2, resulting in inhibition of translation (Dever et al. 1992). Replacing uridine with $\Psi$ diminishes PKR activation (Anderson et al. 2010). Curiously, in the same setting, incorporation of $\mathrm{m}^{6} \mathrm{~A}$ instead of adenosine in mRNAs rendered them untranslatable (Kariko et al. 2008). Recently, Svitkin et al. (2017) showed that $N^{1}$-methyl- $\Psi$ outperforms $\Psi$ and several other nucleoside modifications in translation by combining reduced immunogenicity with altered dynamics of the translation process. Collectively, these findings reveal a complex interplay between mRNA modifications, innate immunity, and translation.

\section{DIFFERENTIAL MRNA MODIFICATION AFFECTS TRANSLATION IN COMPLEX BIOLOGICAL PROCESSES}

Prior to the emergence of high-throughput methods, studies of the $\mathrm{m}^{6} \mathrm{~A}$ methyltransferase METTL3 showed the modification to be necessary for elaborate biological processes requiring differentiation, such as embryogenesis in Arabidopsis thaliana (Zhong et al. 2008) and oogenesis in Drosophila melanogaster (Hongay and Orr-Weaver 2011). The involvement of $\mathrm{m}^{6} \mathrm{~A}$ in fertility was substantiated when a study of the $\mathrm{m}^{6} \mathrm{~A}$ demethylase ALKBH5 showed that dysregulated $\mathrm{m}^{6} \mathrm{~A}$ levels in mice, as a result of ALKBH5 knockout, led to defects in spermatogenesis, possibly because of dysregulated splicing and mRNA expression (Zheng et al. 2013; Tang et al. 2017).

Following the mapping of $\mathrm{m}^{6} \mathrm{~A}$ in mammalian cells, which revealed the extent and conservation of the modification, its role in differentiation was explored further. Although the first study of $\mathrm{m}^{6} \mathrm{~A}$ in mouse embryonic stem cells (mESCs) found, by knockdown of the methyltransferases Mettl3 and Mettl14, that $\mathrm{m}^{6} \mathrm{~A}$ is required for self-renewal of mESCs (Zhu et al.
2014), we and others found that complete knockout of Mettl3 in mESCs abrogates the ability of mESCs to undergo differentiation (Batista et al. 2014; Geula et al. 2015). Differentiation is a cellular process that is hypothesized to require concerted and timely degradation of pluripotency factors, and depletion of $\mathrm{m}^{6} \mathrm{~A}$ leads to continued expression of pluripotency factors, such as Nanog and Oct4, even as differentiation is triggered. The continued expression of the more stable pluripotent mRNAs, because of their reduced $\mathrm{m}^{6} \mathrm{~A}$ levels, results in their higher protein levels (Geula et al. 2015).

Another tightly controlled process, early embryogenesis, requires clearance of maternal mRNAs in maternal-to-zygotic transition (MZT) (Lee et al. 2014). Zhao et al. (2017) neatly showed the importance of YTHDF2-mediated removal of $\mathrm{m}^{6} \mathrm{~A}$-methylated maternal transcripts for MZT in zebrafish.

The cellular response to stress presents another system that relies on prompt shifts in expression patterns. When we mapped the $\mathrm{m}^{6} \mathrm{~A}$ methylome, we noticed a dynamic response to various stimuli, such as ultraviolet irradiation and interferon exposure (Dominissini et al. 2012). Recent studies have examined in greater depth the role that $\mathrm{m}^{6} \mathrm{~A}$ plays in the cellular response to stress. In response to heat shock stress, the $\mathrm{m}^{6} \mathrm{~A}$ reader YTHDF2 undergoes stress-induced localization to the nucleus, where it protects $5^{\prime} \mathrm{UTR}$ methylation of pertinent transcripts from demethylation by FTO (Zhou et al. 2015). The protected $\mathrm{m}^{6} \mathrm{~A}$ residues promote cap-independent translation of heat shock protein 70 (Hsp70) mRNA, providing a mechanism for selective translation under heat shock stress. Knockdown of YTHDF2 disrupts this mechanism, leading to reduced synthesis of Hsp70 after exposure to heat shock stress (Zhou et al. 2015). Further evidence of this mechanism is found in the work of Meyer et al. (2015), which describes transcriptome-wide redistribution of $\mathrm{m}^{6} \mathrm{~A}$ in response to diverse cellular stresses, resulting in an increased number of mRNAs with $5^{\prime}$ UTR methylation capable of promoting cap-independent translation, including similar results regarding the translation of $\mathrm{Hsp} 70$ following heat stress. 
More evidence for the role of $\mathrm{m}^{6} \mathrm{~A}$ in regulating translation in response to stress came from researching the role of YTHDF1, where Wang et al. (2015) showed that tethering the noncatalytic amino terminus of YTHDF1 to a transcript augments its translation during recovery from arsenic stress.

Involvement of $\mathrm{m}^{6} \mathrm{~A}$ in response to stress also appears to play a part in carcinogenesis. Zhang et al. (2016a,b) found that exposure of breast cancer cells to hypoxia results in reduced $\mathrm{m}^{6} \mathrm{~A}$ levels in pluripotency factor NANOG and Kruppel-like factor 4 (KLF4) mRNAs because of both inhibited zinc finger protein 217 (ZNF217)-dependent methylation and increased ALKBH5-dependent demethylation, thus increasing their protein levels and, subsequently, the breast cancer stem-cell phenotype. In contrast to the decrease in $\mathrm{m}^{6} \mathrm{~A}$ levels in pluripotency factors in breast cancer cells, examination of the global response of HEK293T cells to hypoxia revealed a general $\mathrm{m}^{6} \mathrm{~A}$ increase in poly(A) RNAs, conferring increased mRNA stability and improved recovery of translational efficiency (Fry et al. 2017).

Reduction in $\mathrm{m}^{6} \mathrm{~A}$ levels has also been found to promote the tumorigenicity and self-renewal of glioblastoma stem-like cells (GSCs) because of altered mRNA expression of key genes (Cui et al. 2017). In addition, increased ALKBH5 expression is seen in GSCs, where it demethylates transcripts of the transcription factor Forkhead Box M1 (FOXM1), thereby enhancing its expression, thus revealing a new pathway for GSC proliferation and tumorigenesis (Zhang et al. 2017).

In acute myeloid leukemia (AML) a different $\mathrm{m}^{6} \mathrm{~A}$ demethylase plays an oncogenic role, although interestingly, by negatively regulating genes important for normal hematopoiesis and differentiation. Unlike the role of ALKBH5 in breast cancer or glioblastoma, FTO promotes leukemogenesis by demethylating target genes, leading to decreased protein levels ( $\mathrm{Li}$ et al. 2017c). In line with this result, METTL3 plays an oncogenic role in AML by methylating coding regions of genes necessary for leukemogenesis, including the oncogene SP1. This methylation relieves ribosome stalling and leads to increased translation. Disruption of this mech- anism resulted in cell-cycle arrest and differentiation of AML cells (Barbieri et al. 2017).

As discussed earlier, $\mathrm{m}^{6} \mathrm{~A}$ also positively regulates expression through the activity of METTL3 in its capacity as an $\mathrm{m}^{6} \mathrm{~A}$ reader. Increased expression of METTL3 in lung adenocarcinoma promotes growth, survival, and invasion of tumor cells (Lin et al. 2016). Some observations of $\mathrm{m}^{6} \mathrm{~A}$ affecting translation are still without mechanistic insight. For example, it has been found that $\mathrm{m}^{6} \mathrm{~A}$ allows a flow of information from transcription to translation, as inefficient transcription results in increased $\mathrm{m}^{6} \mathrm{~A}$ deposition, causing decreased translation efficiency (Slobodin et al. 2017).

Overall, these findings show that differential methylation, or reading thereof, affects translation in complex biological processes, and as a result plays a key role in determining cell fate. Other recently identified mRNA modifications, such as $\mathrm{m}^{1} \mathrm{~A}$ (Dominissini et al. 2016) and $\Psi$ (Schwartz et al. 2014), have been reported to be dynamic in response to stress. Deciphering the roles that they play in translational regulation promises to be an interesting avenue of research.

\section{CONCLUDING REMARKS}

Research on the epitranscriptome has quickly moved from one of identification and mapping to the investigation of function and of the biological implications of mRNA modifications. Studies of the role that these modifications play in translation paint a complex picture. When examining direct regulation of translation, it appears that the same modification can either promote or repress translation of an mRNA, depending on the location of the modification or the biological system studied. Indirectly, the same modification can either increase mRNA stability, as in the case of hypoxia-induced stabilization of mRNA (Fry et al. 2017), or decrease it, as exemplified in the widely studied YTHDF2-mediated decay of $\mathrm{m}^{6} \mathrm{~A}$-methylated mRNA (Wang et al. 2014; Du et al. 2016). These contrasting effects ultimately have different consequences for translation output. With $\mathrm{m}^{6} \mathrm{~A}$, the most studied modification, we are now begin- 
E. Peer et al.

ning to understand that the delicate balance of methylation and demethylation is involved in complex biological processes such as differentiation (Geula et al. 2015) and the stress response (Zhou et al. 2015). Alterations to that balance contribute to different pathologies ( $\mathrm{Li}$ et al. 2017c; Zhang et al. 2017). The epitranscriptome, consisting of various RNA modifications, is thus beginning to be unraveled as a complex layer of information with major implications for the regulation of translation in healthy and disease states. The continued discovery of more modifications, writers, readers, and erasers will help shape our understanding of how RNA modifications participate in biological and pathological processes, and perhaps design effective pharmacological interventions to disease states.

\section{REFERENCES}

${ }^{*}$ Reference is also in this collection.

Amort T, Rieder D, Wille A, Khokhlova-Cubberley D, Riml C, Trixl L, Jia XY, Micura R, Lusser A. 2017. Distinct 5-methylcytosine profiles in poly(A) RNA from mouse embryonic stem cells and brain. Genome Biol 18: 1 .

Anderson BR, Muramatsu H, Nallagatla SR, Bevilacqua PC, Sansing LH, Weissman D, Kariko K. 2010. Incorporation of pseudouridine into mRNA enhances translation by diminishing PKR activation. Nucleic Acids Res 38: 5884-5892.

Barbieri I, Tzelepis K, Pandolfini L, Shi J, Millan-Zambrano G, Robson SC, Aspris D, Migliori V, Bannister AJ, Han N, et al. 2017. Promoter-bound METTL3 maintains myeloid leukaemia by $\mathrm{m}^{6} \mathrm{~A}$-dependent translation control. Nature 552: 126-131.

Batista PJ, Molinie B, Wang J, Qu K, Zhang J, Li L, Bouley DM, Lujan E, Haddad B, Daneshvar K, et al. 2014. $\mathrm{m}^{6} \mathrm{~A}$ RNA modification controls cell fate transition in mammalian embryonic stem cells. Cell Stem Cell 15: 707-719.

Boccaletto P, Machnicka MA, Purta E, Piątkowski P, Bagiński B, Wirecki TK, de Crécy-Lagard V, Ross R, Limbach PA, Kotter A. 2018. MODOMICS: A database of RNA modification pathways. 2017 update. Nucleic Acids Res 46: D303-D307.

Bokar JA. 2005. The biosynthesis and functional roles of methylated nucleosides in eukaryotic mRNA. In Finetuning of RNA functions by modification and editing (ed. Grosjean H), pp. 141-177. Springer, Berlin.

Byszewska M, Śmietański M, Purta E, Bujnicki JM. 2014. RNA methyltransferases involved in $5^{\prime}$ cap biosynthesis. RNA Biol 11: 1597-1607.

Carlile TM, Rojas-Duran MF, Zinshteyn B, Shin H, Bartoli KM, Gilbert WV. 2014. Pseudouridine profiling reveals regulated mRNA pseudouridylation in yeast and human cells. Nature 515: 143-146.
* Chekulaeva M, Rajewsky N. 2018. Roles of long noncoding RNAs and circular RNAs in translation. Cold Spring Harb Perspect Biol doi: 10.1101/cshperspect.a032680.

Choi J, Ieong KW, Demirci H, Chen J, Petrov A, Prabhakar A, O'Leary SE, Dominissini D, Rechavi G, Soltis SM, et al. 2016. $N^{6}$-methyladenosine in mRNA disrupts tRNA selection and translation-elongation dynamics. Nat Struct Mol Biol 23: 110-115.

Cohn WE. 1951. Some results of the applications of ionexchange chromatography to nucleic acid chemistry. J Cell Comp Physiol 38: 21-40.

Coots RA, Liu XM, Mao Y, Dong L, Zhou J, Wan J, Zhang X, Qian SB. 2017. $\mathrm{m}^{6} \mathrm{~A}$ facilitates eIF4F-independent mRNA translation. Mol Cell doi: 10.1016/j.molcel.2017.10.001.

Cui Q, Shi H, Ye P, Li L, Qu Q, Sun G, Sun G, Lu Z, Huang Y, Yang CG, et al. 2017. $\mathrm{m}^{6} \mathrm{~A}$ RNA methylation regulates the self-renewal and tumorigenesis of glioblastoma stem cells. Cell Rep 18: 2622-2634.

Daffis S, Szretter KJ, Schriewer J, Li J, Youn S, Errett J, Lin T-Y, Schneller S, Zust R, Dong H. 2010. 2'-O methylation of the viral mRNA cap evades host restriction by IFIT family members. Nature 468: 452.

Dai Q, Moshitch-Moshkovitz S, Han D, Kol N, Amariglio N, Rechavi G, Dominissini D, He C. 2017. Nm-seq maps $2^{\prime}$-O-methylation sites in human mRNA with base precision. Nat Methods 14: 695-698.

Davis S, Watson JC. 1996. In vitro activation of the interferon-induced, double-stranded RNA-dependent protein kinase PKR by RNA from the $3^{\prime}$ untranslated regions of human $\alpha$-tropomyosin. Proc Natl Acad Sci 93: 508-513.

Delatte B, Wang F, Ngoc LV, Collignon E, Bonvin E, Deplus R, Calonne E, Hassabi B, Putmans P, Awe S, et al. 2016. RNA biochemistry. Transcriptome-wide distribution and function of RNA hydroxymethylcytosine. Science 351: 282-285.

Deryusheva S, Choleza M, Barbarossa A, Gall JG, Bordonné R. 2012. Post-transcriptional modification of spliceosomal RNAs is normal in SMN-deficient cells. RNA 18: 3136.

Desrosiers R, Friderici K, Rottman F. 1974. Identification of methylated nucleosides in messenger RNA from Novikoff hepatoma cells. Proc Natl Acad Sci 71: 3971-3975.

Desrosiers RC, Friderici KH, Rottman FM. 1975. Characterization of Novikoff hepatoma mRNA methylation and heterogeneity in the methylated $5^{\prime}$ terminus. Biochemistry 14: $4367-4374$.

Dever TE, Feng L, Wek RC, Cigan AM, Donahue TF, Hinnebusch AG. 1992. Phosphorylation of initiation factor $2 \alpha$ by protein kinase GCN 2 mediates gene-specific translational control of GCN4 in yeast. Cell 68: 585-596.

Dominissini D, Moshitch-Moshkovitz S, Schwartz S, Salmon-Divon $M$, Ungar L, Osenberg $S$, Cesarkas $K$, Jacob-Hirsch J, Amariglio N, Kupiec M, et al. 2012. Topology of the human and mouse $\mathrm{m}^{6} \mathrm{~A}$ RNA methylomes revealed by $\mathrm{m}^{6} \mathrm{~A}$-seq. Nature 485: 201-206.

Dominissini D, Nachtergaele S, Moshitch-Moshkovitz S, Peer E, Kol N, Ben-Haim MS, Dai Q, Di Segni A, Salmon-Divon M, Clark WC, et al. 2016. The dynamic $N^{1}$-methyladenosine methylome in eukaryotic messenger RNA. Nature 530: 441-446. 
Du H, Zhao Y, He J, Zhang Y, Xi H, Liu M, Ma J, Wu L. 2016. YTHDF2 destabilizes $\mathrm{m}^{6} \mathrm{~A}$-containing RNA through direct recruitment of the CCR4-NOT deadenylase complex. Nat Commun 7: 12626.

Dubin DT, Taylor RH. 1975. The methylation state of poly A-containing messenger RNA from cultured hamster cells. Nucleic Acids Res 2: 1653-1668.

Dubin DT, Stollar V, Hsuchen CC, Timko K, Guild GM 1977. Sindbis virus messenger RNA: The 5'-termini and methylated residues of 26 and 42 S RNA. Virology 77: 457-470.

Edupuganti RR, Geiger S, Lindeboom RGH, Shi H, Hsu PJ, Lu Z, Wang S-Y, Baltissen MPA, Jansen PWTC, Rossa M, et al. 2017. $N^{6}$-methyladenosine $\left(\mathrm{m}^{6} \mathrm{~A}\right)$ recruits and repels proteins to regulate mRNA homeostasis. Nat Struct Mol Biol 24: 870-878.

Fernandez IS, Ng CL, Kelley AC, Wu G, Yu YT, Ramakrishnan V. 2013. Unusual base pairing during the decoding of a stop codon by the ribosome. Nature 500: 107-110.

Fry NJ, Law BA, Ilkayeva OR, Holley CL, Mansfield KD. 2017. $N^{6}$-methyladenosine is required for the hypoxic stabilization of specific mRNAs. RNA 23: 1444-1455.

Fu Y, Dominissini D, Rechavi G, He C. 2014. Gene expression regulation mediated through reversible $\mathrm{m}^{6} \mathrm{~A}$ RNA methylation. Nat Rev Genet 15: 293-306.

Fustin JM, Doi M, Yamaguchi Y, Hida H, Nishimura S, Yoshida M, Isagawa T, Morioka MS, Kakeya H, Manabe I, et al. 2013. RNA-methylation-dependent RNA processing controls the speed of the circadian clock. Cell 155: 793-806.

Ge J, Yu YT. 2013. RNA pseudouridylation: New insights into an old modification. Trends Biochem Sci 38: 210-218.

Geula S, Moshitch-Moshkovitz S, Dominissini D, Mansour AA, Kol N, Salmon-Divon M, Hershkovitz V, Peer E, Mor $\mathrm{N}$, Manor YS, et al. 2015. Stem cells. $\mathrm{m}^{6} \mathrm{~A}$ mRNA methylation facilitates resolution of naïve pluripotency toward differentiation. Science 347: 1002-1006.

Gumienny R, Jedlinski D, Martin G, Vina-Villaseca A, Zavolan M. 2016. High-throughput identification of C/D box snoRNA targets with CLIP and RiboMeth-seq. bioRxiv doi: 10.1101/037259.

He C, Hus JC, Sun LJ, Zhou P, Norman DP, Dotsch V, Wei H, Gross JD, Lane WS, Wagner G, et al. 2005. A methylation-dependent electrostatic switch controls DNA repair and transcriptional activation by E. coli ada. Mol Cell 20: 117-129.

* Heck AM, Wilusz J. 2018. The interplay between the RNA decay and translation machinery in eukaryotes. Cold Spring Harb Perspect Biol doi: 10.1101/cshperspect. a032839.

* Hellen CUT. 2018. Translation termination and ribosome recycling in eukaryotes. Cold Spring Harb Perspect Biol doi: 10.1101/cshperspect.a032656.

Hershey JW, Sonenberg N, Mathews MB. 2012. Principles of translational control: An overview. Cold Spring Harb Perspect Biol 4: a011528.

Hoernes TP, Clementi N, Faserl K, Glasner H, Breuker K, Lindner H, Hüttenhofer A, Erlacher MD. 2016. Nucleotide modifications within bacterial messenger RNAs regulate their translation and are able to rewire the genetic code. Nucleic Acids Res 44: 852-862.
Hongay CF, Orr-Weaver TL. 2011. Drosophila inducer of MEiosis 4 (IME4) is required for Notch signaling during oogenesis. Proc Natl Acad Sci 108: 14855-14860.

Hornung V, Ellegast J, Kim S, Brzozka K, Jung A, Kato H, Poeck H, Akira S, Conzelmann KK, Schlee M, et al. 2006. $5^{\prime}$-triphosphate RNA is the ligand for RIG-I. Science 314: 994-997.

Huang H, Weng H, Sun W, Qin X, Shi H, Wu H, Zhao BS, Mesquita A, Liu C, Yuan CL, et al. 2018. Recognition of RNA $N^{6}$-methyladenosine by IGF2BP proteins enhances mRNA stability and translation. Nat Cell Biol 20: 285295.

Hussain S, Sajini AA, Blanco S, Dietmann S, Lombard P, Sugimoto Y, Paramor M, Gleeson JG, Odom DT, Ule J, et al. 2013. NSun2-mediated cytosine-5 methylation of vault noncoding RNA determines its processing into regulatory small RNAs. Cell Rep 4: 255-261.

Imai Y, Matsuo N, Ogawa S, Tohyama M, Takagi T. 1998. Cloning of a gene, YT521, for a novel RNA splicingrelated protein induced by hypoxia/reoxygenation. Brain Res Mol Brain Res 53: 33-40.

* Ingolia NT, Hussmann JA, Weissman JS. 2018. Ribosome profiling: Global views of translation. Cold Spring Harb Perspect Biol doi: 10.1101/cshperspect.a032698.

Jia G, Fu Y, Zhao X, Dai Q, Zheng G, Yang Y, Yi C, Lindahl T, Pan T, Yang YG, et al. 2011. $N^{6}$-methyladenosine in nuclear RNA is a major substrate of the obesity-associated FTO. Nat Chem Biol 7: 885-887.

Jöckel S, Nees G, Sommer R, Zhao Y, Cherkasov D, Hori H, Ehm G, Schnare M, Nain M, Kaufmann A. 2012. The $2^{\prime}$-O-methylation status of a single guanosine controls transfer RNA-mediated Toll-like receptor 7 activation or inhibition. J Exp Med 209: 235-241.

Karijolich J, Yu YT. 2011. Converting nonsense codons into sense codons by targeted pseudouridylation. Nature 474: 395-398.

Kariko K, Buckstein M, Ni H, Weissman D. 2005. Suppression of RNA recognition by Toll-like receptors: The impact of nucleoside modification and the evolutionary origin of RNA. Immunity 23: 165-175.

Kariko K, Muramatsu H, Welsh FA, Ludwig J, Kato H, Akira S, Weissman D. 2008. Incorporation of pseudouridine into mRNA yields superior nonimmunogenic vector with increased translational capacity and biological stability. Mol Ther 16: 1833-1840.

Keith JM, Ensinger MJ, Mose B. 1978. HeLa cell RNA (2'-Omethyladenosine- $N^{6}$-)-methyltransferase specific for the capped 5'-end of messenger RNA.J Biol Chem 253: 5033 5039.

Khoddami V, Cairns BR. 2013. Identification of direct targets and modified bases of RNA cytosine methyltransferases. Nat Biotechnol 31: 458-464.

Kumar S, Mapa K, Maiti S. 2014. Understanding the effect of locked nucleic acid and 2'-O-methyl modification on the hybridization thermodynamics of a miRNA-mRNA pair in the presence and absence of AfPiwi protein. Biochemistry 53: 1607-1615.

* Kwan T, Thompson SR. 2018. Noncanonical translation in eukaryotes. Cold Spring Harb Perspect Biol doi: 10.1101/ cshperspect.a032672. 
E. Peer et al.

Lacoux C, Di Marino D, Boyl PP, Zalfa F, Yan B, Ciotti MT Falconi M, Urlaub H, Achsel T, Mougin A, et al. 2012. BC1-FMRP interaction is modulated by $2^{\prime}$-O-methylation: RNA-binding activity of the tudor domain and translational regulation at synapses. Nucleic Acids Res 40: 4086-4096.

Lee MT, Bonneau AR, Giraldez AJ. 2014. Zygotic genome activation during the maternal-to-zygotic transition. Annu Rev Cell Dev Biol 30: 581-613.

Li F, Zhao D, Wu J, Shi Y. 2014. Structure of the YTH domain of human YTHDF2 in complex with an $\mathrm{m}^{6} \mathrm{~A}$ mononucleotide reveals an aromatic cage for $\mathrm{m}^{6} \mathrm{~A}$ recognition. Cell Res 24: 1490-1492.

Li X, Zhu P, Ma S, Song J, Bai J, Sun F, Yi C. 2015. Chemical pulldown reveals dynamic pseudouridylation of the mammalian transcriptome. Nat Chem Biol 11: 592-597.

Li X, Ma S, Yi C. 2016a. Pseudouridine: The fifth RNA nucleotide with renewed interests. Curr Opin Chem Biol 33: $108-116$.

Li X, Xiong X, Wang K, Wang L, Shu X, Ma S, Yi C. 2016b. Transcriptome-wide mapping reveals reversible and dynamic $N^{1}$-methyladenosine methylome. Nat Chem Biol 12: 311-316.

Li A, Chen YS, Ping XL, Yang X, Xiao W, Yang Y, Sun HY, Zhu Q, Baidya P, Wang X, et al. 2017a. Cytoplasmic $\mathrm{m}^{6} \mathrm{~A}$ reader YTHDF3 promotes mRNA translation. Cell Res 27: 444-447.

Li X, Xiong X, Zhang M, Wang K, Chen Y, Zhou J, Mao Y, Lv J, Yi D, Chen XW. 2017b. Base-resolution mapping reveals distinct $\mathrm{m}^{1} \mathrm{~A}$ methylome in nuclear-and mitochondrial-encoded transcripts. Mol Cell 68: 993-1005

Li Z, Weng H, Su R, Weng X, Zuo Z, Li C, Huang H, Nachtergaele S, Dong L, Hu C, et al. 2017c. FTO plays an oncogenic role in acute myeloid leukemia as a $N^{6}$-methyladenosine RNA demethylase. Cancer Cell 31: 127-141.

Liang X-h, Liu Q, Fournier MJ. 2009. Loss of rRNA modifications in the decoding center of the ribosome impairs translation and strongly delays pre-rRNA processing. RNA 15: 1716-1728.

Lin J, Lai S, Jia R, Xu A, Zhang L, Lu J, Ye K. 2011. Structural basis for site-specific ribose methylation by box C/D RNA protein complexes. Nature 469: 559-563.

Lin S, Choe J, Du P, Triboulet R, Gregory RI. 2016. The $\mathrm{m}^{6} \mathrm{~A}$ methyltransferase METTL3 promotes translation in human cancer cells. Mol Cell 62: 335-345.

Liu N, Dai Q, Zheng G, He C, Parisien M, Pan T. 2015. $\mathrm{N}^{6}$-methyladenosine-dependent RNA structural switches regulate RNA-protein interactions. Nature 518: 560-564.

Lu L, Yi C, Jian X, Zheng G, He C. 2010. Structure determination of DNA methylation lesions $\mathrm{N}^{1}$-meA and $\mathrm{N}^{3}$-meC in duplex DNA using a cross-linked protein-DNA system. Nucleic Acids Res 38: 4415-4425.

Luo S, Tong L. 2014. Molecular basis for the recognition of methylated adenines in RNA by the eukaryotic YTH domain. Proc Natl Acad Sci 111: 13834-13839.

Mauer J, Luo X, Blanjoie A, Jiao X, Grozhik AV, Patil DP, Linder B, Pickering BF, Vasseur JJ, Chen Q, et al. 2017. Reversible methylation of $\mathrm{m}^{6} \mathrm{Am}$ in the $5^{\prime}$ cap controls mRNA stability. Nature 541: 371-375.
* Merrick WC, Pavitt GD. 2018. Protein synthesis initiation in eukaryotic cells. Cold Spring Harb Perspect Biol doi: 10.1101/cshperspect.a033092.

Meyer K, Jaffrey SR. 2017. Rethinking $\mathrm{m}^{6} \mathrm{~A}$ readers, writers, and erasers. Annu Rev Cell Dev Biol 33: 319-342.

Meyer KD, Saletore Y, Zumbo P, Elemento O, Mason CE, Jaffrey SR. 2012. Comprehensive analysis of mRNA methylation reveals enrichment in $3^{\prime}$ UTRs and near stop codons. Cell 149: 1635-1646.

Meyer KD, Patil DP, Zhou J, Zinoviev A, Skabkin MA, Elemento O, Pestova TV, Qian SB, Jaffrey SR. 2015. $5^{\prime}$ UTR $\mathrm{m}^{6} \mathrm{~A}$ promotes cap-independent translation. Cell 163: 999-1010.

Nallagatla SR, Toroney R, Bevilacqua PC. 2011. Regulation of innate immunity through RNA structure and the protein kinase PKR. Curr Opin Struct Biol 21: 119-127.

Noeske J, Wasserman MR, Terry DS, Altman RB, Blanchard SC, Cate JH. 2015. High-resolution structure of the Escherichia coli ribosome. Nat Struct Mol Biol 22: 336-341.

Patil DP, Chen CK, Pickering BF, Chow A, Jackson C, Guttman M, Jaffrey SR. 2016. $\mathrm{m}^{6}$ A RNA methylation promotes XIST-mediated transcriptional repression. Nature 537: 369-373.

* Robichaud N, Sonenberg N, Ruggero D, Schneider RJ. 2018. Translational control in cancer. Cold Spring Harb Perspect Biol doi: 10.1101/cshperspect.a032896.

* Rodnina MV. 2018. Translation in prokaryotes. Cold Spring Harb Perspect Biol doi: 10.1101/cshperspect.a032664.

Roost C, Lynch SR, Batista PJ, Qu K, Chang HY, Kool ET. 2015. Structure and thermodynamics of $N^{6}$-methyladenosine in RNA: A spring-loaded base modification. J Am Chem Soc 137: 2107-2115.

Roundtree IA, Evans ME, Pan T, He C. 2017. Dynamic RNA modifications in gene expression regulation. Cell 169: 1187-1200.

Schwartz S, Bernstein DA, Mumbach MR, Jovanovic M, Herbst RH, Leon-Ricardo BX, Engreitz JM, Guttman M, Satija R, Lander ES, et al. 2014. Transcriptome-wide mapping reveals widespread dynamic-regulated pseudouridylation of ncRNA and mRNA. Cell 159: 148-162.

Shi H, Wang X, Lu Z, Zhao BS, Ma H, Hsu PJ, Liu C, He C. 2017. YTHDF3 facilitates translation and decay of $N^{6}$. methyladenosine-modified RNA. Cell Res 27: 315-328.

Shubina M, Musinova Y, Sheval E. 2016. Nucleolar methyltransferase fibrillarin: Evolution of structure and functions. Biochemistry (Moscow) 81: 941-950.

Slobodin B, Han R, Calderone V, Vrielink JA, Loayza-Puch F, Elkon R, Agami R. 2017. Transcription impacts the efficiency of mRNA translation via co-transcriptional $N^{6}$-adenosine methylation. Cell 169: 326-337.

Somme J, Van Laer B, Roovers M, Steyaert J, Versées W, Droogmans L. 2014. Characterization of two homologous 2'-O-methyltransferases showing different specificities for their tRNA substrates. RNA 20: 1257-1271.

Squires JE, Patel HR, Nousch M, Sibbritt T, Humphreys DT, Parker BJ, Suter CM, Preiss T. 2012. Widespread occurrence of 5-methylcytosine in human coding and noncoding RNA. Nucleic Acids Res 40: 5023-5033.

Stoilov P, Rafalska I, Stamm S. 2002. YTH: A new domain in nuclear proteins. Trends Biochem Sci 27: 495-497. 
Svitkin YV, Cheng YM, Chakraborty T, Presnyak V, John M, Sonenberg N. 2017. N1-methyl-pseudouridine in mRNA enhances translation through eIF $2 \alpha$-dependent and independent mechanisms by increasing ribosome density. Nucleic Acids Res 45: 6023-6036.

Tang C, Klukovich R, Peng H, Wang Z, Yu T, Zhang Y, Zheng H, Klungland A, Yan W. 2017. ALKBH5-dependent $\mathrm{m}^{6} \mathrm{~A}$ demethylation controls splicing and stability of long $3^{\prime}$-UTR mRNAs in male germ cells. Proc Natl Acad Sci 115: E325-E333.

Theler D, Dominguez C, Blatter M, Boudet J, Allain FH. 2014. Solution structure of the YTH domain in complex with $N^{6}$-methyladenosine RNA: A reader of methylated RNA. Nucleic Acids Res 42: 13911-13919.

Wang Y, Ludwig J, Schuberth C, Goldeck M, Schlee M, Li H, Juranek S, Sheng G, Micura R, Tuschl T, et al. 2010. Structural and functional insights into $5^{\prime}$-ppp RNA pattern recognition by the innate immune receptor RIG-I. Nat Struct Mol Biol 17: 781-787.

Wang X, Lu Z, Gomez A, Hon GC, Yue Y, Han D, Fu Y, Parisien M, Dai Q, Jia G, et al. 2014. $N^{6}$-methyladenosinedependent regulation of messenger RNA stability. Nature 505: $117-120$.

Wang X, Zhao BS, Roundtree IA, Lu Z, Han D, Ma H, Weng X, Chen K, Shi H, He C. 2015. $N^{6}$-methyladenosine modulates messenger RNA translation efficiency. Cell 161: 1388-1399.

Wei CM, Gershowitz A, Moss B. 1976. 5'-Terminal and internal methylated nucleotide sequences in HeLa cell mRNA. Biochemistry 15: 397-401.

* Wek RC. 2018. Role of eIF2 $\alpha$ kinases in translational control and adaptation to cellular stresses. Cold Spring Harb Perspect Biol doi: 10.1101/cshperspect.a032870.

Xiao W, Adhikari S, Dahal U, Chen YS, Hao YJ, Sun BF, Sun HY, Li A, Ping XL, Lai WY, et al. 2016. Nuclear $\mathrm{m}^{6} \mathrm{~A}$ reader YTHDC1 regulates mRNA splicing. Mol Cell 61: 507-519.

Xu C, Wang X, Liu K, Roundtree IA, Tempel W, Li Y, Lu Z, $\mathrm{He}$ C, Min J. 2014. Structural basis for selective binding of $\mathrm{m}^{6} \mathrm{~A}$ RNA by the YTHDC1 YTH domain. Nat Chem Biol 10: 927-929.

Yang X, Yang Y, Sun BF, Chen YS, Xu JW, Lai WY, Li A, Wang X, Bhattarai DP, Xiao W, et al. 2017a. 5-methylcytosine promotes mRNA export-NSUN2 as the methyltransferase and ALYREF as an m5C reader. Cell Res 27: 606-625.

Yang Y, Fan X, Mao M, Song X, Wu P, Zhang Y, Jin Y, Yang Y, Chen LL, Wang Y, et al. 2017b. Extensive translation of circular RNAs driven by $N^{6}$-methyladenosine. Cell Res 27: 626-641.

Yildirim I, Kierzek E, Kierzek R, Schatz GC. 2014. Interplay of LNA and 2'-O-methyl RNA in the structure and thermodynamics of RNA hybrid systems: A molecular
The Epitranscriptome in Translation Regulation

dynamics study using the revised AMBER force field and comparison with experimental results. J Phys Chem B 118: 14177-14187.

You C, Dai X, Wang Y. 2017. Position-dependent effects of regioisomeric methylated adenine and guanine ribonucleosides on translation. Nucleic Acids Res 45: 9059-9067.

Yu J, Chen M, Huang H, Zhu J, Song H, Zhu J, Park J, Ji SJ. 2017. Dynamic $m^{6} A$ modification regulates local translation of mRNA in axons. Nucleic Acids Res 46: 1412-1423.

Zhang Z, Theler D, Kaminska KH, Hiller M, de la Grange P, Pudimat R, Rafalska I, Heinrich B, Bujnicki JM, Allain FH, et al. 2010. The YTH domain is a novel RNA binding domain. J Biol Chem 285: 14701-14710.

Zhang C, Samanta D, Lu H, Bullen JW, Zhang H, Chen I, He X, Semenza GL. 2016a. Hypoxia induces the breast cancer stem cell phenotype by HIF-dependent and ALKBH5mediated $\mathrm{m}^{6} \mathrm{~A}$-demethylation of NANOG mRNA. Proc Natl Acad Sci 113: E2047-E2056.

Zhang C, Zhi WI, Lu H, Samanta D, Chen I, Gabrielson E, Semenza GL. 2016b. Hypoxia-inducible factors regulate pluripotency factor expression by ZNF217- and ALKBH5-mediated modulation of RNA methylation in breast cancer cells. Oncotarget 7: 64527-64542.

Zhang S, Zhao BS, Zhou A, Lin K, Zheng S, Lu Z, Chen Y, Sulman EP, Xie K, Bogler O, et al. 2017. $\mathrm{m}^{6}$ A demethylase ALKBH5 maintains tumorigenicity of glioblastoma stemlike cells by sustaining FOXM1 expression and cell proliferation program. Cancer Cell 31.

Zhao BS, Wang X, Beadell AV, Lu Z, Shi H, Kuuspalu A, Ho RK, He C. 2017. $\mathrm{m}^{6} \mathrm{~A}$-dependent maternal mRNA clearance facilitates zebrafish maternal-to-zygotic transition. Nature 542: 475-478.

Zheng G, Dahl JA, Niu Y, Fedorcsak P, Huang CM, Li CJ, Vagbo CB, Shi Y, Wang WL, Song SH, et al. 2013. ALKBH5 is a mammalian RNA demethylase that impacts RNA metabolism and mouse fertility. Mol Cell 49: 18-29.

Zhong S, Li H, Bodi Z, Button J, Vespa L, Herzog M, Fray RG. 2008. MTA is an Arabidopsis messenger RNA adenosine methylase and interacts with a homolog of a sexspecific splicing factor. Plant Cell 20: 1278-1288.

Zhou J, Wan J, Gao X, Zhang X, Jaffrey SR, Qian SB. 2015. Dynamic $\mathrm{m}^{6} \mathrm{~A}$ mRNA methylation directs translational control of heat shock response. Nature 526: 591-594.

Zhu T, Roundtree IA, Wang P, Wang X, Wang L, Sun C, Tian Y, Li J, He C, Xu Y. 2014. Crystal structure of the YTH domain of YTHDF2 reveals mechanism for recognition of $N^{6}$-methyladenosine. Cell Res 24: 1493-1496.

Züst R, Cervantes-Barragan L, Habjan M, Maier R, Neuman BW, Ziebuhr J, Szretter KJ, Baker SC, Barchet W, Diamond MS. 2011. Ribose 2'-O-methylation provides a molecular signature for the distinction of self and nonself mRNA dependent on the RNA sensor Mda5. Nat Immunol 12: 137-143. 


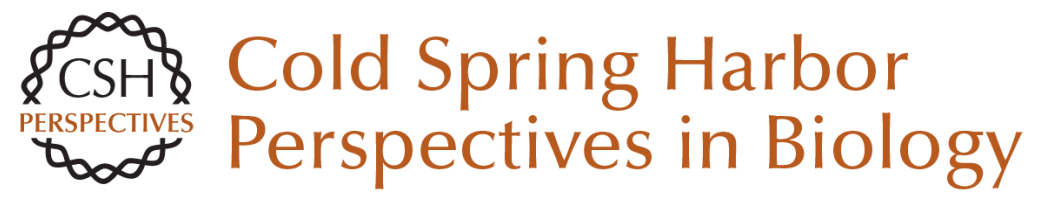

\section{The Epitranscriptome in Translation Regulation}

Eyal Peer, Sharon Moshitch-Moshkovitz, Gideon Rechavi and Dan Dominissini

Cold Spring Harb Perspect Biol 2019; doi: 10.1101/cshperspect.a032623 originally published online July 23, 2018

\section{Subject Collection Translation Mechanisms and Control}

Protein Synthesis and Translational Control: A Historical Perspective

Soroush Tahmasebi, Nahum Sonenberg, John W.B. Hershey, et al.

Translational Control in the Brain in Health and Disease

Wayne S. Sossin and Mauro Costa-Mattioli

Phosphorylation and Signal Transduction

Pathways in Translational Control Christopher G. Proud

Translational Control during Developmental Transitions

$$
\text { Felipe Karam Teixeira and Ruth Lehmann }
$$

Stress Granules and Processing Bodies in Translational Control

Pavel Ivanov, Nancy Kedersha and Paul Anderson

Fluorescence Imaging Methods to Investigate

Translation in Single Cells Jeetayu Biswas, Yang Liu, Robert H. Singer, et al.

Translational Control in Virus-Infected Cells Noam Stern-Ginossar, Sunnie R. Thompson, Michael B. Mathews, et al.

Nonsense-Mediated mRNA Decay Begins Where Translation Ends

Evangelos D. Karousis and Oliver Mühlemann
Principles of Translational Control John W.B. Hershey, Nahum Sonenberg and Michael B. Mathews

The Epitranscriptome in Translation Regulation Eyal Peer, Sharon Moshitch-Moshkovitz, Gideon Rechavi, et al.

Translational Control in Cancer Nathaniel Robichaud, Nahum Sonenberg, Davide Ruggero, et al.

Roles of Long Noncoding RNAs and Circular

RNAs in Translation Marina Chekulaeva and Nikolaus Rajewsky

Ribosome Profiling: Global Views of Translation Nicholas T. Ingolia, Jeffrey A. Hussmann and Jonathan S. Weissman

Noncanonical Translation Initiation in Eukaryotes Thaddaeus Kwan and Sunnie R. Thompson

Mechanistic Insights into MicroRNA-Mediated Gene Silencing Thomas F. Duchaine and Marc R. Fabian

Toward a Kinetic Understanding of Eukaryotic Translation Masaaki Sokabe and Christopher S. Fraser

For additional articles in this collection, see http://cshperspectives.cshlp.org/cgi/collection/

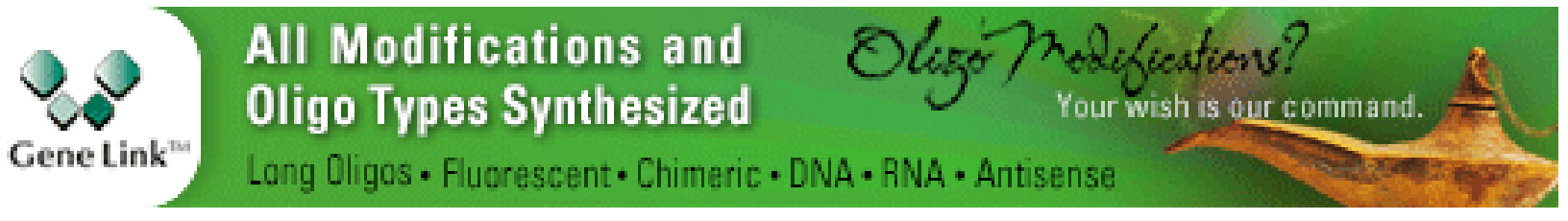

